\title{
Biomarkers in anal cancer: from biological understanding to stratified treatment
}

\author{
Christopher M Jones ${ }^{1,2}$, Vicky Goh ${ }^{3,4}$, David Sebag-Montefiore ${ }^{1,2}$ and Duncan C Gilbert ${ }^{\star, 5}$ \\ ${ }^{1}$ Leeds Cancer Centre, Leeds Teaching Hospitals NHS Trust, Leeds LS9 7TF, UK; ${ }^{2}$ Leeds Institute of Cancer \& Pathology, University \\ of Leeds, Leeds LS9 7TF, UK; ${ }^{3}$ Division of Imaging Sciences and Biomedical Engineering, King's College London, London \\ SE1 7EH, UK; ${ }^{4}$ Department of Radiology, Guy's and St Thomas' NHS Foundation Trust, London SE1 7EH, UK and ${ }^{5}$ Sussex Cancer \\ Centre, Royal Sussex County Hospital, Eastern Road, Brighton BN2 5BE, UK
}

Squamous cell carcinomas of the anus and anal canal represent a model of a cancer and perhaps the first where level 1 evidence supported primary chemoradiotherapy (CRT) in treating locoregional disease with curative intent. The majority of tumours are associated with infection with oncogenic subtypes of human papilloma virus and this plays a significant role in their sensitivity to treatment. However, not all tumours are cured with CRT and there remain opportunities to improve outcomes in terms of oncological control and also reducing late toxicities. Understanding the biology of ASCC promises to allow a more personalised approach to treatment, with the development and validation of a range of biomarkers and associated techniques that are the focus of this review.

Anal squamous cell carcinomas (ASCC) are increasing in frequency across the developed world (Johnson et al, 2004; Wilkinson et al, 2014; Bouvier et al, 2016). Associated with oncogenic subtypes of the human papilloma viruses (HPV; Baricevic et al, 2015) they typically present at a localised stage with or without regional lymph node involvement. Aside from in the earliest tumours, where the majority may be excised surgically, the international standard of care is chemoradiotherapy (CRT). As first appreciated by Nigro et al, ASCC demonstrate marked sensitivity to this combined modality of treatment, which additionally avoids the need for radical surgery and permanent colostomy (Nigro et al, 1983). Although 6 phase III clinical trials have been reported in ASCC investigating alternative chemotherapies, there is no benefit from adjuvant or maintenance chemotherapy and concurrent chemoradiotherapy with Mitomycin, and 5FU remains the standard of care with $65-74 \%$ 3-year local control (Spithoff et al, 2014). However, all have posed clinical questions without any correlative biology or stratification beyond clinical and stage-related prognostic markers.

It is increasingly appreciated that the biology of HPV transformation contributes to the chemo/radio sensitivity seen in ASCC, a characteristic most extensively investigated in head and neck cancer (Swick et al, 2015). An improved understanding of the underlying factors involved in this process, and those that mediate resistance and relapse would offer significant opportunities in improving outcomes across the spectrum of ASCC. Furthermore, as we will detail, ASCC as a model system might provide further insights into cancer biology across the spectrum of HPV-associated malignancies.

\section{TRANSLATIONAL QUESTIONS IN ANAL CANCER}

While the relative sensitivity of ASCC to CRT means that oncologic outcomes appear reasonable, key translational questions remain and for certain groups of patients, outcomes remain poor. Although data around late toxicity from anal cancer CRT is limited (Bentzen et al, 2013) up to $30 \%$ patients experience debilitating side effects, particularly in terms of bowel function. Surgery is currently reserved for relapsing cases, where there is a clear benefit to operating early (Renehan et al, 2005) and as such prompt detection of residual/recurrent disease, or even identification of tumours that are primarily resistant to CRT would have significant clinical benefit.

In terms of utilising biomarkers to improve outcomes, first, factors that are predictive of response would facilitate modulation of components of CRT (i.e., radiotherapy dose or novel combination therapeutics) either aiming to improve response rates in poor risk disease, or potentially de-intensify treatment to avoid excessive

*Correspondence: Dr DC Gilbert; E-mail: duncan.gilbert@bsuh.nhs.uk 
late toxicity (as currently being tested in the setting of head and neck cancers (Owadally et al, 2015)). There is considerable variation in radiotherapy doses used, from the relatively lower doses in the initial series (Nigro et al, 1983), through $50.4 \mathrm{~Gy}$ in ACT2 to 54-64 Gy in the Nordic countries (Leon et al, 2014). Second techniques that aided the early detection of relapse would facilitate prompt salvage surgery with improved outcomes.

In addition, there is the potential to investigate whether underlying genomic factors modulate HPV-induced transformation of cells (Levovitz et al, 2014) and subsequent clinical behaviour or mediate toxicity from radiotherapy as described in prostate cancer (Fachal et al, 2014). An understanding of the mechanisms that mediate relapse, dissemination and resistance will identify technology and targets for future therapy in a disease where currently there is only palliative cytotoxic chemotherapy with limited response rates and poor outcomes.

Importantly, given the ultimate aim of developing any biomarker is to improve clinical outcomes, it is vital that tests are sufficiently robust and reproducible in terms of assay development, and then prospectively validated, ideally in the context of a randomised controlled trial, as detailed in Cancer Research UK's biomarker roadmap; (http:/www.cancerresearchuk.org/sites/ default/files/prognostic_and_predictive.pdf).

\section{CURRENT BIOMARKERS OF RESPONSE TO} CHEMORADIOTHERAPY

A number of variables are reported to contribute to the heterogeneity in outcomes seen in patients with ASCC (Das et al, 2008). These include measurement of the extent of a patient's disease as conferred by the tumour size and nodal status, each of which independently predicts disease-free and overall survival (OS). It has also been reported that initial response to treatment with radiotherapy correlates with the extent of both local control and OS. However, despite their overall prognostic value, clinicopathologic factors do not consistently enable prediction of response to currently available treatment modalities. There therefore remains a requirement for predictive markers to guide clinicians' choice of treatment.

In a previous systematic review of 21 studies published before 2010, Lampejo et al identified 13 biomarkers associated with outcome in ASCC (Lampejo et al, 2010). Of these, only p53 and p21 were shown to have prognostic utility in more than one study, yet their value was not universally supported by the reported literature. Other reported prognostic biomarkers - testable markers postulated to provide information relating to a patient's outcome included numerous tumour suppressor genes, apoptotic regulators, tumour markers and factors involved in angiogenesis, proliferation and invasion.

A number of subsequent retrospective analyses have highlighted the potential prognostic utility of identifying tumour HPV involvement, either directly or through analysis of its surrogate marker, p16 overexpression. A systematic search of PubMed (August 2006-August 2016) using the terms: p16 AND/OR HPV/ human papilloma virus AND outcome OR prognosis/prognostic AND anal squamous cell carcinoma OR anal carcinoma was performed. Only those relating to the specific prognostic utility of $\mathrm{HPV} / \mathrm{p} 16$ in anal squamous cell carcinoma patients managed with chemoradiotherapy were selected. References of those papers selected to be of potential relevance based on their abstract were also reviewed.

As shown in Table 1, OS, recurrence and both locoregional and systemic failure are reported to correlate with high p16 expression and the presence of HPV DNA. Given that the prevalence of HPV DNA is universally reported to be high, additional prognostic subsets have been generated through the detection of the specific HPV genotype HPV16, either alone or in combination with p16.

The most widely studied outcome with respect to HPV/p16 status is OS. In univariate analyses, significant associations have been reported between 3- to 10-year survival and both p16 expression and the detection of HPV and HPV16 DNA. There nevertheless remain inconsistencies and in the studies included here, p16 status significantly correlated with OS in only half of the patient populations in which it was analysed. Though reported in fewer manuscripts, both recurrence and locoregional failure have also been consistently significantly associated with HPV, HPV16 and p16 status. This is in contrast to systemic failure, which to our knowledge significantly correlates with HPV/p16 status in only two reports to date.

In multivariate analyses, HPV16 and p16 are both reported to be independently predictive of PFS and OS (Yhim et al, 2011; Gilbert et al, 2013; Ravenda et al, 2014; Serup-Hansen et al, 2014; Baricevic et al, 2015; Mai et al, 2015; Rodel et al, 2015). Mai et al additionally report an independent association between combined $\mathrm{HPV} / \mathrm{p} 16$ status and PFS (Mai et al, 2015). In contrast, Koerber and Meulendijks identified no independent associations for HPV or p16 alone, but reported combined HPV and p16 to be predictive of both PFS and OS (Koerber et al, 2014; Meulendijks et al, 2015).

The studies outlined here are retrospective and small. Median follow-up ranges between 27.9-59.0 months, over which time the outcomes of between 47 and 110 patients were studied. This may contribute to the inconsistencies in the outcomes reported here. However, given that the majority of tumours are HPV positive (noting that not all HPV DNA-positive ASCC, and particularly those solely p16-positive, can be causally related to HPV (Prigge et al, 2016) where the gold standard to indicate a transcriptionally active (transforming) HPV infection is detection of E6/E7 mRNA (von Knebel Doeberitz, 2016)) additional biomarkers over and above HPV status are required to guide treatment stratification.

\section{MOLECULAR MECHANISMS FOR DIFFERENTIAL} SENSITIVITY TO CRT IN HPV \pm CASES

Improved technologies (predominately next generation sequencing) have begun to offer explanations for the differential sensitivities seen between HPV + and - ve tumours, accepting the subtleties of this distinction as detailed above. As previously discussed, increased protein expression of p53 (associated with mutations that cause the protein to remain detectable) has previously been associated with worse outcomes after CRT and is inversely correlated with p16/HPV (Gilbert et al, 2013). Sequencing data confirms that p53 mutations and HPV involvement are for the most part mutually exclusive in ASCC (Meulendijks et al, 2015) being found in HPV - ve cases in a manner parallel to that seen in head and neck cancer (Westra et al, 2008). Inactivation of p53 seems to be an essential step in tumourigenesis. In HPV + ve tumours this arises through the action of HPV E6, though potentially this can be overcome if sufficient DNA damage (i.e.,CRT) occurs. In the absence of E6 (i.e., HPV - ve cases), such suppression of activity must arise through mutation, meaning p53 activity is unrecoverable and DNA damage goes undetected (Figure 1).

A number of studies have used broader genomic profiling to investigate cohorts of ASCC, using a mixture of pre-treatment biopsies and samples from relapsing patients. A combination of immunohistochemistry, in situ hybridisation and targeted sequencing was applied to 199 ASCC (Smaglo et al, 2015). A total of $89 \%$ cases expressed EGFR, though amplification was infrequent (7.4\%) and no mutations were recorded. The most commonly mutated gene was PIK3CA (33\% samples) with TP53 second most frequent in $15 \%$. Further evidence of the high frequency of these mutations 


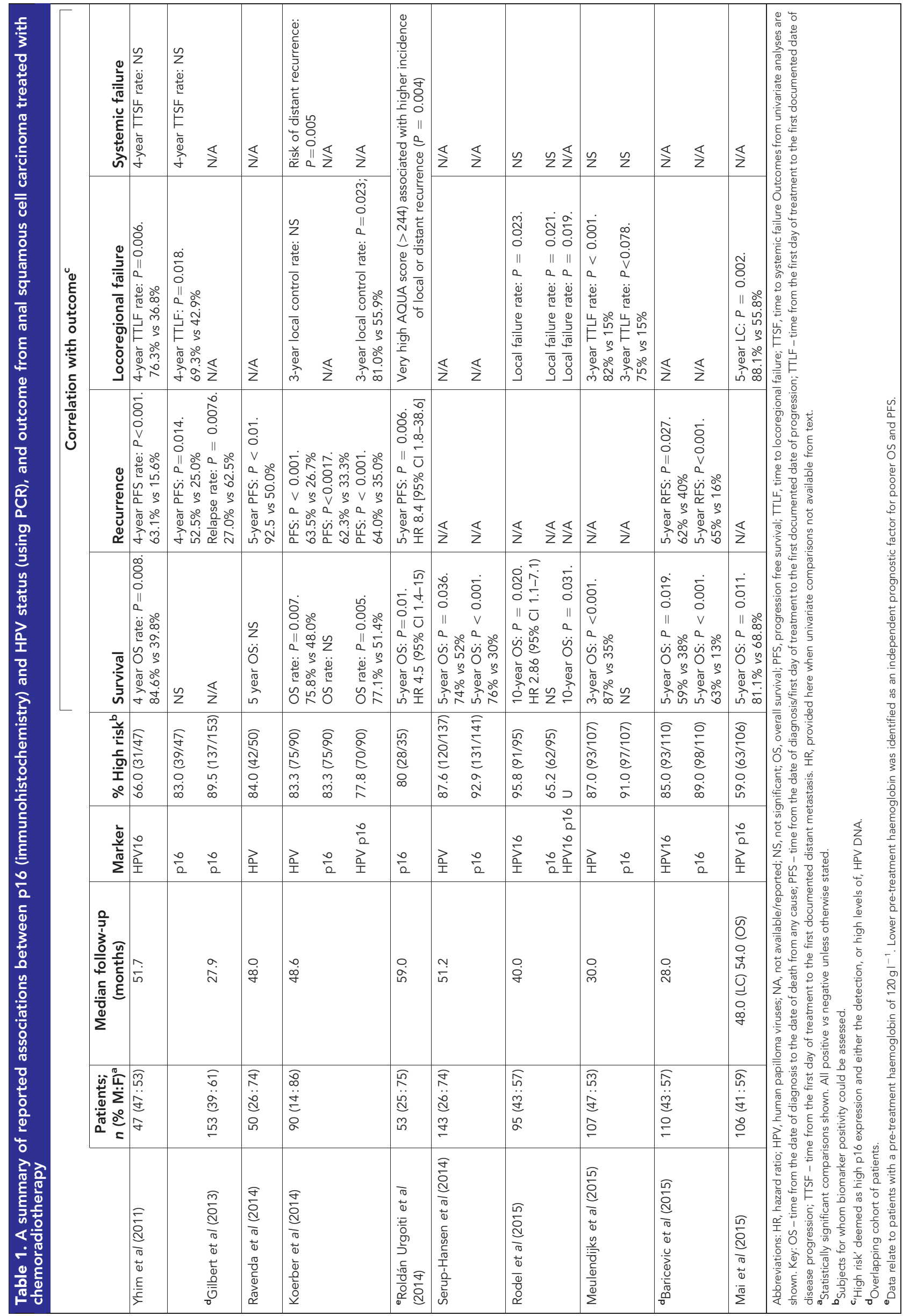




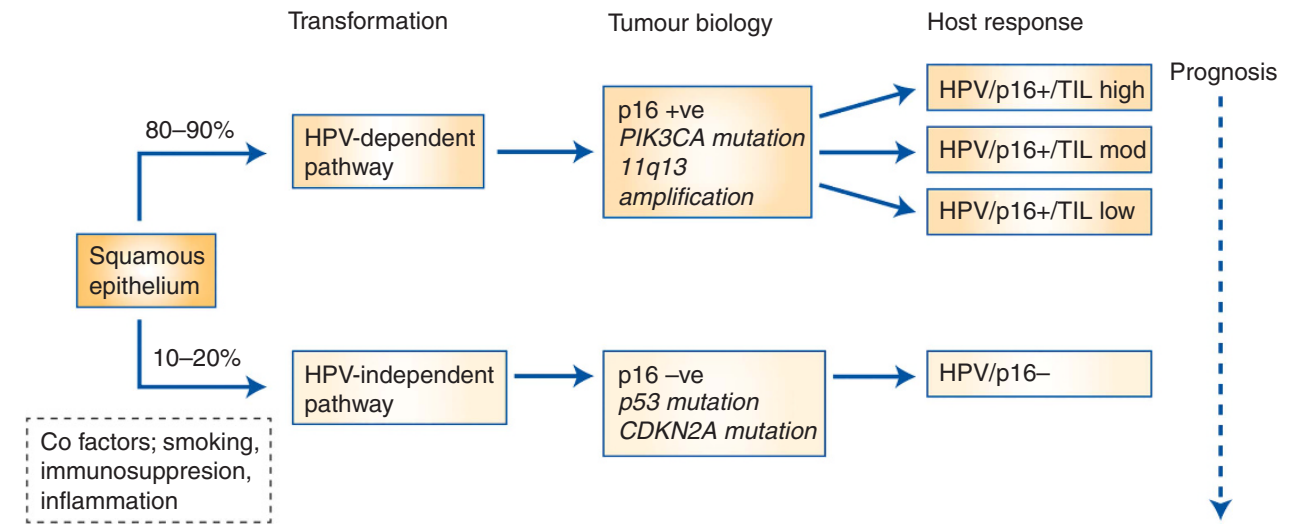

Figure 1. A biological model of response to chemoradiotherapy in ASCC.

comes from data (using a 236 gene NGS panel) from 70 anal cancers (Chung et al, 2016). In total, $87 \%$ were HPV positive. The most frequent mutations again involved PIK3CA (40\% cases), with PTEN loss seen in an additional 14\%. TP53 and CDKN2a mutations were seen predominately in HPV negative cases where 6/9 tumours had mutations in TP53 mutation, and 5/9 CDKN2A. Five cases (all HPV + ve) had amplification at 11q13 (a region that includes FGF3, FGF4, FGF19 and CCND1). No associations between these molecular abnormalities and tumour stage or clinical behaviour were reported.

A recent study (Cacheux et al, 2016) provides further evidence for these relationships, sequencing 8 genes (KRAS, NRAS, HRAS, BRAF, PIK3CA, MET, TP53 and FBXW7) in 148 ASCC patients including 52 recurrences post CRT. A total of 30 patients (20.3\%) demonstrated PIK3CA mutations and 7 patients (4.7\%) demonstrated mutations in TP53, the latter only seen in recurrent tumours and associated with HPV - ve tumours (3/131 HPV + ve vs 4/17 HPV - ve). Three had mutations in KRAS whereas NRAS, HRAS and BRAF were wild-type throughout.

The importance of PI3 kinase signalling in ASCC, predominately through a high frequency of activating PIK3CA mutations, is a feature of other HPV-associated squamous cell carcinomas. In total, 30\% cervical cancers harbour PIK3CA mutations associated with poor outcomes following chemoradiotherapy (McIntyre et al, 2013; de la Rochefordiere et al, 2015), but similar findings are also reported in vulval (Trietsch et al, 2014) and penile cancers (McDaniel et al, 2015). Similarly the inverse relationship between HPV involvement and TP53 mutations is documented in HNSCC (Westra et al, 2008) and vulval cancer (Trietsch et al, 2014).

\section{HOST IMMUNE RESPONSE AND OUTCOME FROM CRT}

The mutational profiling demonstrates differing routes to transformation $(\mathrm{HPV} \pm$ ) that appear to impact on clinical outcomes. However, the host response to ASCC is also a powerful arbiter of the effectiveness of CRT. One phenotypic readout of the local immune response can be seen in the extent of infiltration of lymphocytes into the tumour. Measurement of tumour infiltrating lymphocytes (TIL) adds prognostic value to HPV status in head and neck cancer (Ward et al, 2014), where patients with HPV + ve tumours but low levels of TILs had similar outcomes (PFS and OS) as HPV - ve cases. In HPV + ve HNSCC cases TIL status outperformed smoking and T-stage as prognostic variables. Importantly, from a mechanistic perspective, these cohorts included patients with HNSCC treated with surgery, suggesting a prognostic effect of both HPV status and TIL across treatment modalities (and hence not simply related to sensitivity to CRT through TP53 mutations as discussed earlier).
Parallel findings have been demonstrated in ASCC (Gilbert et al, 2016). Using cohorts of ASCC from the UK and Denmark treated with CRT with published clinical outcomes and known HPV status (Gilbert et al, 2013; Serup-Hansen et al, 2014), high levels of TIL showed improved outcomes in the HPV + ve patients, whereas patients with low levels of TIL had outcomes more in keeping with HPV - ve tumours. This finding requires validation in a cohort of samples large enough for robust multivariate analysis to include all clinical and radiological factors but raises the possibility that modulating the host response to the tumour could improve therapeutic response.

Lymphocyte infiltrates represent a visual readout of the local host response, but a more detailed understanding (e.g., relative CD4/CD8 and antibody responses) of the nature of this response should facilitate improved prognostic ability and important opportunities for therapeutic intervention.

\section{PLASMA-BASED MONITORING OF DISEASE}

Anal Cancer presents a compelling case for developing serial, noninvasive markers of response/relapse, given that the tumour is treated in situ with chemoradiotherapy, and may go on to display a complete response only after many months of follow up (GlynneJones et al, 2012). Surgical salvage is possible, but undesirable if a complete response is achieved. Predictive markers that allow real time analysis (and may be prospectively compared with imaging results) would be of significant clinical benefit. For those tumours with residual/recurrent active disease, prompt surgical salvage is associated with improved outcomes (Renehan et al, 2005); the prognosis following $\mathrm{R} 1$ resection is poor.

Squamous Cell Carcinoma Antigen (SCCA) is a member of the Serpin supergroup of proteins and raised plasma levels have been reported across a number of squamous cancers including cervix, head and neck. With respect to anal cancer, levels at baseline have been reported to have prognostic value. Specifically $49 \%$ of 174 patients demonstrated raised plasma SCCA (Williams et al, 2013) at presentation, correlating with reduced complete response to treatment and reduced disease-free and OS. More recently there has been interest in SCCA in follow up where one small study of 24 patients was not consistent with respect to baseline prognosis, but during follow up, 2 patients demonstrated a rise of SCCA, one of whom developed recurrence and metastatic disease (Henkenberens et al, 2016).

More advanced techniques to use plasma-based assays that inform on the biology of disease are now coming of age (O'Leary and Turner, 2016) where changes in circulating tumour DNA may be a more sensitive and specific way to predict outcome to therapy through treatment (Garcia-Murillas et al, 2015). 
Longitudinal analysis of cell free DNA is of particular interest, as HPV DNA sequences, integrated into the genomes of anal cancer, represent a unique signature of ongoing cellular activity given the ubiquity of HPV in this cancer type (Baricevic et al, 2015). This technique has recently been reported using HPV transcripts in cervical cancer (Campitelli et al, 2012) and head and neck cancer (Rutkowski et al, 2015) in a parallel setting (post chemoradiotherapy). Not all HPV-associated tumours harbour integrated viral genomes and additionally some of the tumours at highest risk of relapse will be truly HPV negative, so alternative cfDNA targets will also be required for disease monitoring. Importantly, prospective assessment of such cfDNA in anal cancer is required to define the performance characteristics of these tests as compared with and correlated with differing imaging modalities and followup schedules.

Similarly there is evidence that microRNAs are involved in $\mathrm{HPV}$-induced transformation of cells in cervical and head and neck cancers at least (Lajer et al, 2012) and potentially mediating response to treatment. By their nature microRNAs are relatively stable and again are being investigated in other HPV-associated tumour types as longitudinal markers of disease state (Summerer et al, 2015).

IMAGING-BASED PROGNOSTIC FACTORS, DETECTION OF RELAPSE AND FUTURE POTENTIAL

A comprehensive review of imaging biomarkers for anal cancer is beyond the scope of this review, but clearly approaches to refine treatment plans and optimise response assessment will require integration of both biological and imaging parameters. The role of imaging in treatment stratification and assessment of response/ relapse has evolved in recent years reflecting the technological advances that have enabled high resolution anatomical imaging to be combined with functional imaging techniques, exemplified by multi-parametric magnetic resonance imaging (MRI) (Jones et $a l, 2015)$ and 18-F fluorodeoxyglucose positron emission tomography (18F-FDG PET) either integrated with computed tomography (CT) (Jones et al, 2015) or more recently with MRI (Goh et al, 2016). Combining the metabolic information from 18F-FDG PET with the high spatial and contrast resolution of anatomical MRI allows accurate delineation of the primary tumour and locoregional nodes for staging and radiotherapy planning, particularly with the incorporation of diffusionweighted MRI (Mandegaran et al, 2016) and also prognostic information (Mohammadkhani et al, 2016).

Following therapy, early size-based MRI evaluation (within 8 weeks of completed therapy) has its limitations (Goh et al, 2010) due to co-located radiotherapy changes; however, a tumour regression grade (TRG) score may have promise in identifying patients who would benefit from salvage surgery (Kochhar et al, 2016). Resolution of 18F-FDG PET activity is effective in detecting complete responders although persistent low grade metabolic activity may not necessarily reflect residual tumour activity (Schwarz et al, 2008). More recently imaging radiomic approaches have been investigated as potential imaging biomarkers in the therapy response setting. The texture heterogeneity information captured by these post-processing tools appear to augment current morphological assessment. Greater MRI heterogeneity may be apparent post-therapy in non-responders (Prezzi et al, 2016), and in the future integrated radiomic approaches combining imaging, clinical and pathological information may allow a more personalised approach to anal cancer management. Again, however, clinical utility will require sufficient levels of quality assurance and reproducibility and validation in prospective studies (O'Connor et al, 2016).
ONGOING TRIALS AND TRANSLATIONAL OPPORTUNITIES

One key question in ASCC is whether the prognostic effect seen through TILs can be manipulated via stimulating the host immune response, either through immune checkpoint inhibition or therapeutic vaccination. Immune checkpoint inhibitors have demonstrated encouraging responses in metastatic ASCC (Ott et al, 2015; Morris et al, 2016). There are a range of potential therapeutic vaccine approaches currently in development (Khallouf et al, 2014), and clinical trials of one such approach underway in both metastatic and locoregional anal cancer (NCT01671488; A Phase I/II Evaluation of ADXS11-001, Mitomycin, 5-fluorouracil (5-FU) and IMRT for Anal Cancer). An important component of these studies in ASCC should be to ascertain whether either strategy can elicit increases in the local/systemic immune response where little is currently seen (i.e., improve outcomes in the HPV - ve or TIL low groups) or whether these novel approaches work best in tumours that already elicit a response (i.e., might facilitate reduced intensity treatment).

An alternative approach is to personalise radiotherapy doses by our current understanding of risk, aiming to intensify treatment for poor risk tumours, and test whether lower doses (and potentially less toxicity) can safely be administered to those with a better prognosis. Cancer Research UK has recently funded the PLATO platform of clinical trials (ISRCTN88455282). The three trials, ACT3, 4 and 5, are designed to personalise the use and dose of radiotherapy across the locoregional disease spectrum (SebagMontefiore et al, 2016). These studies provide an ideal platform for the prospective analysis/validation of a number of the biomarkers discussed here and potentially answer questions around whether increased radiotherapy dose can make up for biologically aggressive features and/or tumours with favourable biology can be cured with less toxic regimens.

Finally, an improved understanding of the molecular biology of anal cancer integrated with associated biomarkers and therapeutic agents might yet allow ASCC patients to benefit from a targeted approach. In the setting of relapsed or metastatic disease, the consistent activation of PI3 kinase signalling through frequent PIK3CA mutation (seen across the HPV-associated tumours) supports the development of clinical trials in this setting. Preclinical data supports this approach with mTOR inhibition showing evidence of efficacy in anal cancer models (Sun et al, 2013). The clinical trial platforms currently being developed can then be adapted to test these approaches as studies and data progress.

A challenge to all these approaches will be in sourcing the biological material to facilitate further understanding and develop biomarker driven trials. A combined approach encouraging additional biopsies (both at diagnosis, during treatment or at relapse), increased use of plasma-based detection and ongoing improvements in technology will be required to maximise output. Achieving this within the context of clinical trials brings the potential to then properly validate such biomarkers to optimise future treatment.

\section{CONCLUSIONS}

SCCA is a tumour where the primary treatment modality is chemoradiotherapy, with surgery as salvage. As such it provides a model system for comprehensive translational science investigating $\mathrm{HPV}$-associated cellular transformation, staging and stratification of treatment protocols and response assessment with outputs relevant across the spectrum of HPV-associated tumours (oropharynx, cervix, vulva) and beyond. 
Our current understanding of prognostic biomarkers offers insights into how biological factors mediate disease progression and response. Integrating this understanding into current and future clinical trials should in the future allow the improved stratification of treatment and facilitate novel therapeutic intervention to improve outcomes for all patients with the disease.

\section{CONFLICT OF INTEREST}

The authors declare no conflict of interest.

\section{REFERENCES}

Baricevic I, He X, Chakrabarty B, Oliver AW, Bailey C, Summers J, Hampson L, Hampson I, Gilbert DC, Renehan AG (2015) High-sensitivity human papilloma virus genotyping reveals near universal positivity in anal squamous cell carcinoma: different implications for vaccine prevention and prognosis. Eur J Cancer 51: 776-785.

Bentzen AG, Balteskard L, Wanderås EH, Frykholm G, Wilsgaard T, Dahl O, Guren MG (2013) Impaired health-related quality of life after chemoradiotherapy for anal cancer: late effects in a national cohort of 128 survivors. Acta Oncol 52: 736-744.

Bouvier AM, Belot A, Manfredi S, Jooste V, Uhry Z, Faivre J, Duport N, Grabar S. French network of cancer registries FRANCIM (2016) Trends of incidence and survival in squamous-cell carcinoma of the anal canal in France: a population-based study. Eur J Cancer Prev 25(3): 182-187.

Cacheux W, Rouleau E, Briaux A, Tsantoulis P, Mariani P, Richard-Molard M, Buecher B, Dangles-Marie V, Richon S, Lazartigues J, Jeannot E, Farkhondeh F, Sastre-Garau X, de La Rochefordière A, Labib A, Falcou MC, Stevens D, Roth A, Roman-Roman S, Mitry E, Bièche I, Lièvre A (2016) Mutational analysis of anal cancers demonstrates frequent PIK3CA mutations associated with poor outcome after salvage abdominoperineal resection. Br J Cancer 114(12): 1387-1394.

Campitelli M, Jeannot E, Peter M, Lappartient E, Saada S, de la Rochefordière A, Fourchotte V, Alran S, Petrow P, Cottu P, Pierga JY, Lantz O, Couturier J, Sastre-Garau X (2012) Human papillomavirus mutational insertion: specific marker of circulating tumor DNA in cervical cancer patients. PLoS One 7: e43393.

Chung JH, Sanford E, Johnson A, Klempner SJ, Schrock AB, Palma NA, Erlich RL, Frampton GM, Chalmers ZR, Vergilio J, Rubinson DA, Sun JX, Chmielecki J, Yelensky R, Suh JH, Lipson D, George Jr TJ, Elvin JA, Stephens PJ, Miller VA, Ross JS, Ali SM (2016) Comprehensive genomic profiling of anal squamous cell carcinoma reveals distinct genomically defined classes. Ann Oncol 27(7): 1336-1341.

Das P, Crane CH, Eng C, Ajani JA (2008) Prognostic factors for squamous cell cancer of the anal canal. Gastrointest Cancer Res 2(1): 10-14.

de la Rochefordiere A, Kamal M, Floquet A, Thomas L, Petrow P, Petit T, Pop M, Fabbro M, Kerr C, Joly F, Sevin E, Maillard S, Curé H, Weber B, Brunaud C, Minsat M, Gonzague L, Berton-Rigaud D, Aumont M, Gladieff L, Peignaux K, Bernard V, Leroy Q, Bieche I, Margogne A, Nadan A, Fourchotte V, Diallo A, Asselain B, Plancher C, Armanet S, Beuzeboc P, Scholl SM (2015) PIK3CA pathway mutations predictive of poor response following standard radiochemotherapy \pm cetuximab in cervical cancer patients. Clin Cancer Res 21: 2530-2537.

Fachal L, Gómez-Caamaño A, Barnett GC, Peleteiro P, Carballo AM, Calvo-Crespo P, Kerns SL, Sánchez-García M, Lobato-Busto R, Dorling L, Elliott RM, Dearnaley DP, Sydes MR, Hall E, Burnet NG, Carracedo Á, Rosenstein BS, West CM, Dunning AM, Vega A (2014) A three-stage genome-wide association study identifies a susceptibility locus for late radiotherapy toxicity at 2q24.1. Nat Genet 46: 891-894.

Garcia-Murillas I, Schiavon G, Weigelt B, Ng C, Hrebien S, Cutts RJ, Cheang M, Osin P, Nerurkar A, Kozarewa I, Garrido JA, Dowsett M, Reis-Filho JS, Smith IE, Turner NC (2015) Mutation tracking in circulating tumor DNA predicts relapse in early breast cancer. Sci Transl Med 7: 302ra133.

Gilbert DC, Serup-Hansen E, Linnemann D, Høgdall E, Bailey C, Summers J, Havsteen H, Thomas GJ (2016) Tumour-infiltrating lymphocyte scores effectively stratify outcomes over and above p16 post chemo-radiotherapy in anal cancer. Br J Cancer 114(2): 134-137.

Gilbert DC, Williams A, Allan K, Stokoe J, Jackson T, Linsdall S, Bailey CM, Summers J (2013) p16INK4A, p53, EGFR expression and KRAS mutation status in squamous cell cancers of the anus: correlation with outcomes following chemo-radiotherapy. Radiother Oncol 109: 146-151.

Glynne-Jones R, James R, M.H., Begum R, Cunningham D, Northover J, Ledermann JA, Beare S, Kadalayil L, Sebag-Montefiore D (2012) Optimum time to assess complete clinical response (CR) following chemoradiation (CRT) using mitomycin (MMC) or cisplatin (CisP), with or without maintenance $\mathrm{Cis} / 5 \mathrm{FU}$ in squamous cell carcinoma of the anus: Results of ACT II. ASCO Annual Meeting Abstracts 30(Suppl 15): 4004.

Goh V, Gollub FK, Liaw J, Wellsted D, Przybytniak I, Padhani AR, Glynne-Jones R (2010) Magnetic resonance imaging assessment of squamous cell carcinoma of the anal canal before and after chemoradiation: can MRI predict for eventual clinical outcome? Int $J$ Radiat Oncol Biol Phys 78: 715-721.

Goh V, Prezzi D, Mallia A, Bashir U, Stirling JJ, John J, Charles-Edwards G, MacKewn J, Cook G (2016) Positron emission tomography/magnetic resonance imaging of gastrointestinal cancers. Semin Ultrasound CT MR 37: 352-357.

Henkenberens C, Toklu H, Tamme C, Bruns F (2016) Clinical value of squamous cell carcinoma antigen (SCCAg) in anal cancer-a single-center retrospective analysis. Anticancer Res 36: 3173-3177.

Johnson LG, Madeleine MM, Newcomer LM, Schwartz SM, Daling JR (2004) Anal cancer incidence and survival: the surveillance, epidemiology, and end results experience, 1973-2000. Cancer 101(2): 281.

Jones M, Hruby G, Solomon M, Rutherford N, Martin J (2015) The role of FDG-PET in the initial staging and response assessment of anal cancer: a systematic review and meta-analysis. Ann Surg Oncol 22: 3574-3581.

Jones M, Hruby G, Stanwell P, Gallagher S, Wong K, Arm J, Martin J (2015) Multiparametric MRI as an outcome predictor for anal canal cancer managed with chemoradiotherapy. BMC Cancer 15: 281.

Khallouf H, Grabowska AK, Riemer AB (2014) Therapeutic vaccine strategies against human papillomavirus. Vaccines (Basel) 2: 422-462.

Koerber SA, Schoneweg C, Slynko A, Krug D, Haefner MF, Herfarth K, Debus J, Sterzing F, von Knebel Doeberitz M, Prigge ES, Reuschenbach M (2014) Influence of human papillomavirus and p16(INK4a) on treatment outcome of patients with anal cancer. Radiother Oncol 113: 331-336.

Lajer CB, Garnæs E, Friis-Hansen L, Norrild B, Therkildsen MH, Glud M, Rossing M, Lajer H, Svane D, Skotte L, Specht L, Buchwald C, Nielsen FC (2012) The role of miRNAs in human papilloma virus (HPV)-associated cancers: bridging between HPV-related head and neck cancer and cervical cancer. Br J Cancer 106(9): 1526-1534.

Lampejo T, Kavanagh D, Clark J, Goldin R, Osborn M, Ziprin P, Cleator S (2010) Prognostic biomarkers in squamous cell carcinoma of the anus: a systematic review. Br J Cancer 103: 1858-1869.

Leon O, Guren M, Hagberg O, Glimelius B, Dahl O, Havsteen H, Naucler G, Svensson C, Tveit KM, Jakobsen A, Pfeiffer P, Wanderås E, Ekman T, Lindh B, Balteskard L, Frykholm G, Johnsson A (2014) Anal carcinomasurvival and recurrence in a large cohort of patients treated according to Nordic guidelines. Radiother Oncol 113(3): 352-358.

Levovitz C, Chen D, Ivansson E, Gyllensten U, Finnigan JP, Alshawish S, Zhang W, Schadt EE, Posner MR, Genden EM, Boffetta P, Sikora AG (2014) TGFbeta receptor 1: an immune susceptibility gene in HPVassociated cancer. Cancer Res 74: 6833-6844.

Mai S, Welzel G, Ottstadt M, Lohr F, Severa S, Prigge ES, Wentzensen N, Trunk MJ, Wenz F, von Knebel-Doeberitz M, Reuschenbach M (2015) Prognostic relevance of HPV Infection and p16 overexpression in squamous cell anal cancer. Int J Radiat Oncol Biol Phys 93: 819-827.

Mandegaran R, Prezzi D, Gourtsoyianni S, Siddique M, Leslie M, GlynneJones R, Goh V (2016) Maximum tumour diameter and gross tumour volume measurement in anal canal cancer: comparison of T2-weighted versus diffusion-weighted MRI. Eur Congr Radiol Vienna.

McDaniel AS, Hovelson DH, Cani AK, Liu CJ, Zhai Y, Zhang Y, Weizer AZ, Mehra R, Feng FY, Alva AS, Morgan TM, Montgomery JS, Siddiqui J, Sadis S, Bandla S, Williams PD, Cho KR, Rhodes DR, Tomlins SA (2015) Genomic profiling of penile squamous cell carcinoma reveals new opportunities for targeted therapy. Cancer Res 75: 5219-5227.

McIntyre JB, Wu JS, Craighead PS, Phan T, Köbel M, Lees-Miller SP, Ghatage P, Magliocco AM, Doll CM (2013) PIK3CA mutational status and overall survival in patients with cervical cancer treated with radical chemoradiotherapy. Gynecol Oncol 128: 409-414.

Meulendijks D, Tomasoa NB, Dewit L, Smits PH, Bakker R, van Velthuysen ML, Rosenberg EH, Beijnen JH, Schellens JH, Cats A (2015) HPV-negative squamous cell carcinoma of the anal canal is unresponsive to standard 
treatment and frequently carries disruptive mutations in TP53. Br J Cancer 112: $1358-1366$.

Mohammadkhani Shali S, Schmitt V, Behrendt FF, Winz OH, Heinzel A, Mottaghy FM, Eble MJ, Verburg FA (2016) Metabolic tumour volume of anal carcinoma on (18)FDG PET/CT before combined radiochemotherapy is the only independant determinant of recurrence free survival. Eur J Radiol 85: 1390-1394.

Morris VK, Ciombor KK, Salem ME, Nimeiri HS, Iqbal S, Singh PP, Polite BN, Deming DA, Chan E, Wade JL, Bekaii-Saab TS, Uronis HE, Pasia MG, Bland G, Wolff RA, Ohinata A, Ohaji C, Rogers J, Sharma P, Eng C (2016) NCI9673: A multi-institutional eETCTN phase II study of nivolumab in refractory metastatic squamous cell carcinoma of the anal canal (SCCA). J Clin Oncol 34(suppl): abstr 3503.

Nigro ND, Seydel HG, Considine B, Vaitkevicius VK, Leichman L, Kinzie JJ (1983) Combined preoperative radiation and chemotherapy for squamous cell carcinoma of the anal canal. Cancer 51: 1826-1829.

O'Connor JP, Aboagye EO, Adams JE, Aerts HJ, Barrington SF, Beer AJ, Boellaard R, Bohndiek SE, Brady M, Brown G, Buckley DL, Chenevert TL, Clarke LP, Collette S, Cook GJ, de Souza NM, Dickson JC, Dive C, Evelhoch JL, Faivre-Finn C, Gallagher FA, Gilbert FJ, Gillies RJ, Goh V, Griffiths JR, Groves AM, Halligan S, Harris AL, Hawkes DJ, Hoekstra OS, Huang EP, Hutton BF, Jackson EF, Jayson GC, Jones A, Koh DM, Lacombe D, Lambin P, Lassau N, Leach MO, Lee TY, Leen EL, Lewis JS, Liu Y, Lythgoe MF, Manoharan P, Maxwell RJ, Miles KA, Morgan B, Morris S, Ng T, Padhani AR, Parker GJ, Partridge M, Pathak AP, Peet AC, Punwani S, Reynolds AR, Robinson SP, Shankar LK, Sharma RA, Soloviev D, Stroobants S, Sullivan DC, Taylor SA, Tofts PS, Tozer GM, van Herk M, Walker-Samuel S, Wason J, Williams KJ, Workman P, Yankeelov TE, Brindle KM, McShane LM, Jackson A, Waterton JC (2016) Imaging biomarker roadmap for cancer studies. Nat Rev Clin Oncol; e-pub ahead of print 11 October 2016; doi:10.1038/nrclinonc.2016.162.

O'Leary B, Turner NC (2016) Science in focus: circulating tumour DNA as a liquid biopsy. Clin Oncol 28(12): 735-738.

Ott PA, Piha-Paul SA, Munster P, Pishvaian MJ, Van Brummelen E, Cohen R, Gomez-Roca C, Ejadi S, Stein M, Chan E, Simonelli M, Morosky A, Yuan SS, Koshiji M, Bennouna J (2015) in European Cancer Congress, Vienna.

Owadally W, Hurt C, Timmins H, Parsons E, Townsend S, Patterson J, Hutcheson K, Powell N, Beasley M, Palaniappan N, Robinson M, Jones TM, Evans M (2015) PATHOS: a phase II/III trial of risk-stratified, reduced intensity adjuvant treatment in patients undergoing transoral surgery for Human papillomavirus (HPV) positive oropharyngeal cancer. BMC Cancer 15: 602 .

Prezzi D, Widjono A, Bonello V, Gourtsoyinanni S, Leslie M, Gaya A, GlynneJones R, Goh V (2016) in European Congress of Radiology, Vienna.

Prigge ES, von Knebel Doeberitz M, Reuschenbach M (2016) Clinical relevance and implications of HPV-induced neoplasia in different anatomical locations. Mutat Res. available online 22 June 2016.

Ravenda PS, Magni E, Botteri E, Manzotti M, Barberis M, Vacirca D, Trovato CM, Dell'Acqua V, Leonardi MC, Sideri M, Fazio N, Zampino MG (2014) Prognostic value of human papillomavirus in anal squamous cell carcinoma. Cancer Chemother Pharmacol 74: 1033-1038.

Renehan AG, Saunders MP, Schofield PF, O'Dwyer ST (2005) Patterns of local disease failure and outcome after salvage surgery in patients with anal cancer. Br J Surg 92: 605-614.

Rodel F, Wieland U, Fraunholz I, Kitz J, Rave-Fränk M, Wolff HA, Weiss C, Wirtz R, Balermpas P, Fokas E, Rödel C (2015) Human papillomavirus DNA load and p16INK4a expression predict for local control in patients with anal squamous cell carcinoma treated with chemoradiotherapy. Int $J$ Cancer 136: 278-288.

Roldán Urgoiti GB, Gustafson K, Klimowicz AC, Petrillo SK, Magliocco AM, Doll CM (2014) The prognostic value of HPV status and p16 expression in patients with carcinoma of the anal canal. PLoS One 9: e108790.

Rutkowski T, AM, Mirosław Ś, Hajduk A, Wygoda A, Widłak P, Składowski K (2015) Circulating HPV DNA as a marker of treatment failure in patients with HPV-related head and neck caner treated with radiochemotherapy. Proceedings of the International Papillomavirus Conference, Lisbon.
Schwarz JK, Siegel BA, Dehdashti F, Myerson RJ, Fleshman JW, Grigsby PW (2008) Tumor response and survival predicted by post-therapy FDG-PET/ CT in anal cancer. Int J Radiat Oncol Biol Phys 71: 180-186.

Sebag-Montefiore D, Adams R, Bell S, Berkman L, Gilbert DC, Glynne-Jones R, Goh V, Gregory W, Harrison M, Kachnic LA, Lee MT, McParland L, Muirhead R, O'Neill BD, Hutchins GG, Rao S, Renehan A, Smith A, Velikova G, Hawkins MA (2016) The development of an umbrella trial (PLATO) to address radiotherapy dose questions in the loco-regional management of squamous cell carcinoma of the anus. Int J Radiat Oncol Biol Phys 96: E164-E165.

Serup-Hansen E, Linnemann D, Skovrider-Ruminski W, Høgdall E, Geertsen PF, Havsteen $\mathrm{H}$ (2014) Human papillomavirus genotyping and p16 expression as prognostic factors for patients with American Joint Committee on Cancer stages I to III carcinoma of the anal canal. J Clin Oncol 32: 1812-1817.

Smaglo BG, Tesfaye A, Halfdanarson TR, Meyer JE, Wang J, Gatalica Z, Reddy S, Arguello D, Boland PM (2015) Comprehensive multiplatform biomarker analysis of 199 anal squamous cell carcinomas. Oncotarget 6: 43594-43604.

Spithoff K, Cummings B, Jonker D, Biagi JJ. Gastrointestinal Cancer Disease Site, G (2014) Chemoradiotherapy for squamous cell cancer of the anal canal: a systematic review. Clin Oncol (R Coll Radiol) 26: 473-487.

Summerer I, Unger K, Braselmann H, Schuettrumpf L, Maihoefer C, Baumeister P, Kirchner T, Niyazi M, Sage E, Specht HM, Multhoff G, Moertl S, Belka C, Zitzelsberger H (2015) Circulating microRNAs as prognostic therapy biomarkers in head and neck cancer patients. $\mathrm{Br} J$ Cancer 113(1): 76-82.

Sun ZJ, Zhang L, Zhang W, Hall B, Bian Y, Kulkarni AB (2013) Inhibition of mTOR reduces anal carcinogenesis in transgenic mouse model. PLoS One 8: e74888.

Swick AD, Chatterjee A, De Costa AM, Kimple RJ (2015) Modulation of therapeutic sensitivity by human papillomavirus. Radiother Oncol 116: 342-345.

Trietsch MD, Spaans VM, ter Haar NT, Osse EM, Peters AA, Gaarenstroom KN, Fleuren GJ (2014) CDKN2A(p16) and HRAS are frequently mutated in vulvar squamous cell carcinoma. Gynecol Oncol 135: 149-155.

von Knebel Doeberitz M (2016) The causal role of human papillomavirus infections in non-anogenital cancers. It's time to ask for the functional evidence. Int J Cancer 139(1): 9-11.

Ward MJ, Thirdborough SM, Mellows T, Riley C, Harris S, Suchak K, Webb A, Hampton C, Patel NN, Randall CJ, Cox HJ, Jogai S, Primrose J, Piper K, Ottensmeier CH, King EV, Thomas GJ (2014) Tumour-infiltrating lymphocytes predict for outcome in HPV-positive oropharyngeal cancer. $\mathrm{Br} \mathrm{J}$ Cancer 110: 489-500.

Westra WH, Taube JM, Poeta ML, Begum S, Sidransky D, Koch WM (2008) Inverse relationship between human papillomavirus-16 infection and disruptive p53 gene mutations in squamous cell carcinoma of the head and neck. Clin Cancer Res 14: 366-369.

Wilkinson JR, Morris EJ, Downing A, Finan PJ, Aravani A, Thomas JD, Sebag-Montefiore D (2014) The rising incidence of anal cancer in England 1990-2010: a population-based study. Colorectal Dis 16: O234-O239.

Williams M, Swampillai A, Osborne M, Mawdsley S, Hughes R, Harrison M, Harvey R, Glynne-Jones R. Mount Vernon Colorectal Cancer Network (2013) Squamous cell carcinoma antigen: a potentially useful prognostic marker in squamous cell carcinoma of the anal canal and margin. Cancer 119: 2391-2398.

Yhim HY, Lee NR, Song EK, Kwak JY, Lee ST, Kim JH, Kim JS, Park HS, Chung IJ, Shim HJ, Hwang JE, Kim HR, Nam TK, Park MR, Shim H, Park HS, Kim HS, Yim CY (2011) The prognostic significance of tumor human papillomavirus status for patients with anal squamous cell carcinoma treated with combined chemoradiotherapy. Int J Cancer 129: 1752-1760.

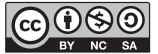

This work is licensed under the Creative Commons Attribution-Non-Commercial-Share Alike 4.0 International License. To view a copy of this license, visit http:// creativecommons.org/licenses/by-nc-sa/4.0/

(C) The Author(s) named above 2017 